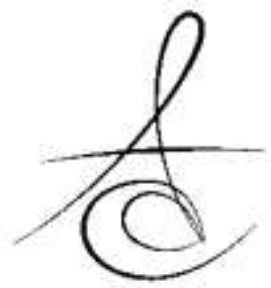

\title{
BİYOAKTİVİTENİN RESTORATİF DİŞ HEKİMLİĞİNDEKİ ÖNEMİ VE BU KONUDAKİ GÜNCEL ÇALIŞMALARIN DERLENMESİ
}

\section{IMPORTANCE OF BIOACTIVITY IN RESTORATIVE DENTISTRY AND A REVIEW OF CURRENT STUDIES ABOUT THIS SUBJECT}

\author{
Dok. Öğr. Dilara YÜREKTEN* Doç. Dr. Arzu PINAR ERDEM*
}

Makale Kodu/Article code: 3753

Makale Gönderilme tarihi: 26.06.2018

Kabul Tarihi: 05.12.2018

DOI : $10.17567 /$ ataunidfd.492657
Dilara Yürekten: ORCID ID: 0000-0001-5015-4399

Arzu Pinar Erdem: ORCID ID: 0000-0002-3940-4761

\section{öz}

Biyoaktif materyaller; materyal arayüzünde, doku ve materyal arasında bağlantı oluşturacak nitelikte özel bir biyolojik cevap ortaya çıkaran materyallerdir. Geçmişten günümüze tıp ve diş hekimliğinde geniş kullanım alanı bulan biyoaktif materyaller; diş hekimliğinde endodontik materyal, kalıcı restoratif materyal, simantasyon ajanı, hassasiyet giderici materyal, fissür örtücü ve remineralize edici materyal olarak pek çok alanda kullanılmaktadır. Biyoaktif materyaller restoratif materyal olarak kullanıldıklarında kalsiyum ve fosfat gibi minerallerin salınımını yaparak doğal remineralizasyon sağlamakta, böylece diş yapısını güçlendirmekte ve materyal-diş arayüzünde oluşturduğu hidroksiapatit tabakası ile sızdırmazlığı sağlayarak ikincil çürük oluşumunu elimine edebilmektedirler. Bu makalenin amaçları, estetik özellikleri ve dayanıkılıklarıyla restoratif diş hekimliğinin geleceğinde önemli bir yere sahip olacağı düşünülen biyoaktif materyaller ile ilgili geçmişten günümüze yapılan çalışmaları incelemek ve güncel yaklaşımları sunmaktır.

Anahtar kelimeler: Biyouyumlu materyaller, kalsiyum fosfat, kalııı diş restorasyonları, diş remineralizasyonu

\section{ABSTRACT}

Bioactive materials are the materials that elicit a specific biological response which provides a connection between the material and tissue at the interface. Bioactive materials which have been used in medicine and dentistry from past to present are used in many fields of dentistry as endodontic and permanent restorative materials, luting agents, desensitizers, fissur sealents and remineralizing materials. Using bioactive materials as restorative materials provides a natural remineralisation mechanism which strengthen the tooth structure by releasing calcium and phosphate minerals, and elimination of secondary caries by sealing the material-tooth interface with a hydroxyapatite layer. The aims of this article are to investigate the studies from past to present about bioactive materials which are considered to have an important role in the future of restorative dentistry with their properties of endurance and esthetics, and to present the current approaches.

Keywords: Biocompatible materials, calcium phosphate, permanent dental restorations, tooth remineralization

\section{* İstanbul Üniversitesi Diș Hekimliği Fakültesi Pedodonti AD, İstanbul}

Kaynakça Bilgisi: Yürekten D, Pınar Erdem A. Biyoaktivitenin Restoratif Diş Hekimliğindeki Önemi Ve Bu Konudaki Güncel Çalışmaların Derlenmesi. Atatürk Üniv Diş Hek Fak Derg 2020; 30: 337-345.

Citation Information: Yurekten D, Pinar Erdem A. Importance of Bioactivity in Restorative Dentistry and A Review of Current Studies About This Subject. J Dent Fac Atatürk Uni 2020; 30: 337-345.

\section{GİRİş}

'Biyoaktif' kelimesi, yunanca bio (hayat) sözcüğü ile latince activus (dinamik, aktivite içeren) sözcüğünün birleşmesinden oluşmaktadır. Bu aktivite; bir yaşam formunu, bir fonksiyonu veya bir süreci ifade edebilir. Bilimsel dilde ise "biyoaktif" kavramı "biyolojik olarak aktif" anlamına gelmektedir. Biyoaktif bileşik ise biyolojik aktiviteye sahip madde olarak ifade edilmektedir. ${ }^{1}$ Bunun yanı sıra, 'biyoaktif' kavramının biyoindüktif veya biyomimetik kavramlarıyla karıştırılmaması gerektiği vurgulanmaktadır. Biyoindüktif etki bir materyalin biyolojik bir sistemde tepki uyandırmasıyken; biyomimetik fonksiyon ise yapay mekanizmalar tarafından doğal yapının taklit edilmesi olarak tanımlanmaktadır. $^{2}$

Medikal sözlüklerde geçen biyoaktif madde kavramı, "yaşayan bir doku üzerinde etki gösteren, bir reaksiyona neden olan veya bir cevabı tetikleyen madde" olarak yer almaktadır. ${ }^{1}$ 'Biyoaktif materyal' 
kavramı 1960'ı yılların sonunda Dr. Larry Hench'in kalsiyum silika fosfat camı, yani Bioglass'ı geliştirmesi ile ortaya çıkmıştır. ${ }^{3}$ Hench L, biyoaktif materyali materyal arayüzünde, doku ve materyal arasında bağlantı oluşturacak nitelikteki özel bir biyolojik cevap ortaya çıkaran materyal olarak tanımlamıştır. ${ }^{4}$

Biyoaktif camların (BAC) in vivo implantasyonlarının toksisiteye, enflamasyona veya olumsuz bir vücut cevabına neden olmadığı gösterilmiştir. ${ }^{5}$ Aynı zamanda biyoaktif camların osteojenik potansiyelleriyle ilgili yapılan çalışmalar biyoaktif ve rezorbe olabilen camların ve bunların iyonik çözünme ürünlerinin, osteoblast proliferasyonunu, farklılaşmasını ve gen ekspresyonunu düzenleyerek osteogenezisi artırdığını göstermiştir. ${ }^{6} \mathrm{Bu}$ camların kemiğe hidroksiapatit tabaka formasyonu ile tutundukları ve materyal iyon konsantrasyonları insan kan plazmasına benzer olan simüle edilmiş vücut sıvıSı (SVS) ortamına konulduğunda da aynı tabakanın görüldüğü bildirilmiştir. $^{7}$

Biyoaktif materyal tanımı 2014 yılında, Dr. Steven Jefferies tarafından genişletilmiş ve diş hekimliğine uygun hale getirilmiştir. Jefferies'in tanımına göre, biyoaktif materyal inorganik fosfat solüsyonu varlığında apatit benzeri yüzey tabakası oluşturan materyaldir. $^{8}$ Uluslararası Standartlar Organizasyonu (International Standards Organization, ISO 23317: 2007)'nun belirlediği standartlara göre; materyal SVS içeren inorganik fosfat solüsyonunda 28 gün içerisinde ölçülebilir bir yüzey apatit tabakası oluşturmalıdır. ${ }^{3}$

Diş hekimliğindeki ideal bir biyoaktif materyalin bakterisidal, bakteriostatik, steril, dentin formasyonunu stimüle edici ve pulpa vitalitesini koruyucu nitelikte olması gerektiği belirtilmektedir. ${ }^{8}$

Biyolojik olarak aktif materyaller diş hekimliğinde sıkça kullanılmakta ve bu konu güncel olarak araştırılmaktadır.

\section{Diş Hekimliğinde Kullanılan Biyoaktif}

\section{Materyaller ve Kullanım Alanları}

Diş hekimliğinde kullanılan biyoaktif materyallerin kullanım alanları şu şekilde özetlenebilir: Remineralizasyon tedavisinde biyomateryaller (BAC ve kazein fosfopeptid-amorf kalsiyum fosfat gibi) diş remineralizasyonunu desteklemektedir. ${ }^{9}$ Ayrıca dentin hassasiyetinin giderilmesinde ${ }^{10}$, fissür örtücü olarak ${ }^{11}$, kalıcı restoratif materyal (Kalsiyum alümina seramik, biyoaktif cam ilave edilmiş cam iyonomer simanlar veya kompozit rezinler, tetrakalsiyum fosfat (TTCP) ilave edilmiş cam iyonomer siman, gümüş takviyeli biyoaktif cam (AG-BC) ile modifiye edilmiş kompozit ve biyoaktif rezin matriks içeren kompozitler) olarak ve endodontik tedavilerde (Kalsiyum Hidroksit $\left(\mathrm{Ca}(\mathrm{OH})_{2}\right.$ ), Mineral Trioksit Agregat (MTA) pulpa kaplaması, kökkanal dolgu patı, apeksifikasyon, rezorpsiyon ve perforasyon tamirinde; Biodentin pulpa kaplaması, apeksifikasyon pulpotomi, perforasyon tamirinde, geçici restoratif materyal olarak ve rezorpsiyon tamirinde; Bioagregat perforasyon ve rezorpsiyon tamirinde, apeksifikasyon ve pulpa kaplamasında; iRoot SP ve iRoot BP gibi biyoseramik esaslı materyaller kanal dolgu patı ve kök tamir materyali olarak $^{8}$; Therecal gibi kalsiyum silika bazlı materyaller direkt ve indirekt pulpa kaplama- $s$ snda ${ }^{12}$ ) ve simantasyon ajanı olarak ${ }^{8}$ kullanılmaktadır.

\section{Restoratif Diş Hekimliğinde Biyoaktif Materyallerin Yeri}

Biyoaktivite kavramının, diş hekimliği için yeni bir terim olmadığı ve bu terimin diş hekimliği literatürüne girmesinin kalsiyum silika veya kalsiyum alümina bazlı materyallerle başlamadığı bildirilmektedir. Cam iyonomer simanların dinamik bir şekilde florid salma özelliklerinden dolayı uzun yıllar biyoaktif materyal olarak kabul edildikleri belirtilmiştir. 1970'li yıllarda geliştirilen cam iyonomer simanların etkinliği, polialkenoik asit ve alüminosilikat cam arasındaki asitbaz reaksiyonuna dayanmaktadır. ${ }^{13}$ Ancak cam iyonomer simanların günümüzde, biyoaktivitenin tanımlanan şekliyle, hidroksiapatit salgılamadığı; geleneksel cam iyonomer simanlardan salınan poliakrilik asitin $\mathrm{pH}^{\prime} \mathrm{yı}$ düşürdüğü, dolayısıyla apatit oluşumunu engellediği bildirilmektedir. ${ }^{14}$ Cam iyonomer siman ve rezin modifiye cam iyonomer simanların bir dönem biyoaktif olarak kabul edilme nedenleri, devamlı fluorid salınımlarından ötürü restorasyon kenarlarındaki ikincil çürük gelişimini geciktirebilmeleri veya tamamen engelleyebilmeleri olarak düşünülmüştür. ${ }^{15}$ Bununla birlikte, cam iyonomerler ile yapılan bazı çalışmalarda ikincil çürüklere rastlanması, başarısızlık olarak kabul edilmiş ${ }^{16}$ ve belirli endikasyonlar için uygun materyaller oldukları kabul edilmesine rağmen diş çürüğünü önleme yetenekleri tartışmalara neden olmuştur. ${ }^{8}$ Materyalin mekanik özellikleri de diğer restoratif materyallere kıyasla yetersiz kabul edilmekte ve bu durum araştırma konusu olmaya devam etmektedir. ${ }^{17}$

Gerek içeriğine biyoaktif camlar eklenerek gerekse diğer çeşitli mekanizmalar kullanılarak, cam iyonomer simanlar biyoaktivite konusunda sıkça başvurulan materyaller olmuştur. Biyoaktif cam iyonomer simanların biyoaktivite mekanizmasında; kalsiyum ve fosfat iyonları, camdan salınarak yüzeyde kalsiyum ve 
fosfattan zengin bir tabaka oluşturmaktadır. Bu tabakanın başlangıçta amorf olduğu, sonrasında hidroksil karbonat apatit (HCA) kristalize olduğu belirtilmiştir. Bu sürecin, çözeltideki karbonat anyonlarının amorf kalsiyum fosfat fazına dahil edilmesi ile gerçekleştiği, HCA'nın çekirdeklenme ve olgunlaşma mekanizmasının sulu silika varlığında in vivo ve in vitro olarak aynı olduğu bildirilmiştir. Bu basamakların materyalin yüzeyinde oluştuğu, oluşması için herhangi bir doku varlığına ihtiyaç olmadığı, distile su veya SVS içerisinde de gerçekleşebildiği; çözülen iyonların salındığı, sulu silikanın yüksek konsantrasyonlarda olduğu ve polikristalin HCA'nın cam yüzeyinde oluştuğu belirtilmiştir. ${ }^{18,19}$

Çeşitli çalışmalarda ise biyoaktiviteyi geliştirmek, dişin rejerasyon ve rekonstrüksiyon kapasitesini artırmak için BAC, cam iyonomer yapısı ile birleştirilmiştir. ${ }^{19}$ Bu bağlamda Yli-Urpo ve ark., (2005), biyoaktif camı (S53P4) cam iyonomer simanların içerisine koyarak çeşitli çalışmalar yapmışlardır. ${ }^{20,21}$ Araştırmaların sonuçlarına göre elde edilen deneysel materyalin biyolojik olarak aktif olup; hem antibakteriyal etkisi bulunduğu, hem de uygun fizyolojik şartlar altında insan dentinini remineralize edebildiği belirtilmiştir. ${ }^{19}$

Restoratif diş hekimliğinin genel sorunlarından biri de restorasyonlu dişlerin tekrar tedavi intiyacıdır. Restoratif diş hekimliğinin üçte ikisini başarısız restorasyonların yenilenmesinin oluşturduğu bildirilmektedir. Restorasyonlu çoğu dişin, zaman içerisinde pulpa tedavisi veya kanal tedavisi gerektiren semptomlar gösterdiği; hatta çoğunun çekim endikasyonu ile sonuçlandığı vurgulanmıştır. ${ }^{22}$

Rezin kompozitler ise sağladıkları estetik ve direkt doldurma imkanı ile restoratif diş hekimliğinde sıklıkla tercih edilen materyallerdir. ${ }^{23}$ Buna rağmen rezin kompozit restorasyonların en sık yenilenme nedeni, diş yüzeyindeki aktif bakteri kolonizasyonunun materyal ve diş dokusu arasındaki mikro boşluklardan dental pulpaya doğru penetre olması ile gerçekleşen mikrosızıntı olarak bildirilmiştir. Rezin bazlı kompozitlerde zaman içinde oluşan kütle çatlaklarının ve diğer restoratif materyallere göre yüzeylerinde daha fazla plak birikiminin, bu materyallerin diğer önemli dezavantajları olduğu da belirtilmiştir. ${ }^{24}$

Geleneksel kompozit restorasyonların pasif olduğu ve dişte az miktarda kimyasal korunma sağladığı kabul edilmektedir ve bunun bir sorun oluşturduğu düşünülmektedir. Önceki yıllara ait kaynaklarda; pasif restoratif materyaller ağız ve çevresi ile en az etkileşimde bulunduğundan oral çevreye en az zararı ver- diğine inanılmış ve bu nedenle iyi materyaller oldukları olduğu belirtilmiştir. Bu düşünce, kompozit yüzeylerinde yüksek konsantrasyonda biyofilm birikimine bağlı olarak ikincil çürüklerin artışı ile şüpheli hale gelmiştir. ${ }^{25}$

Khvostenko ve ark., (2016), rezin kompozite BAC ekleyerek kullanmışlar, simüle diş dolgularının kenar boşluklarındaki bakteriyel biyofilm penetrasyonunu in vitro olarak incelemişlerdir. Kenar boşluklarındaki bakteriyel penetrasyonun ortalama derinliği, BAC15 içeren örneklerde (\%61) BAC içermeyen örneklere göre (\%100) anlamlı derecede daha az bulunmuştur. Çalışma sonucunda BAC içeren rezin kompozitlerin restorasyon kenarlarındaki ikincil çürük gelişimini yavaşlatabileceği belirtilmiştir. ${ }^{26}$

Çevreyle olan etkileşimlerine göre, dental materyaller şu şekilde kategorize edilmektedir; biyoinert (pasif), biyoaktif, biyo-duyarlı ve akıllı materyaller. ${ }^{27}$ Akılı materyaller, çevresel uyaranlara göre cevap değiştirebilen materyaller olarak tanımlanmaktadır. ${ }^{19}$ Mevcut dental materyalleri daha uzun ömürlü, akıllı, biyoaktif ve antibakteriyel özellikli hale getirmek için çalışmalar yapılmaya devam edilmektedir. ${ }^{28,29} \mathrm{Bu}$ çalışmaların çoğu silikon sodyum, kalsiyum ve fosfor oksitten oluşan ${ }^{19}$ biyoaktif camların eklenmesi ile biyolojik etkinliğin arttığına dair kanıt sağlamaktadır. Biyoaktif camların, dentin yüzeylerinin mineralizasyonunu uyardığı bildirilmiştir. ${ }^{30}$ Elde edilen sonuçlar; biyoaktif cam içeren dental materyallerin, etkilenmiş diş dokularının remineralizasyonuna yardımcı olabileceğini destekler niteliktedir. ${ }^{20}$

Kalsiyumun hasarlı dokunun restorasyonu için kritik bir materyal olduğu, dentin ve minede bulunan hidroksiapatitin temel yapısını oluşturduğu bilinmektedir. Kalsiyum hidroksit, uzun yıllar boyunca çevre diş dokuları üzerindeki remineralizasyon etkisi sebebiyle pulpa kaplama ajanı olarak kullanılmıştır. ${ }^{31}$ Materyalin pH'yı artırma özelliği, çevre yumuşak dokularda irritasyona neden olduğundan, kullanım alanlarını sınırlandırmıştır. Hidroksil iyonunun negatif etkilerini gidermek ve aynı zamanda kalsiyum iyonlarından yararlanabilmek için kompozit materyallerine kalsiyum fosfatlar eklenmiştir. ${ }^{32}$ Kalsiyumun yanı sıra, mine ve dentinin çözünürlüğünü azaltarak diş dokusunda fluoroapatit oluşumu sağlayan ve hasarlı dişi remineralize edebilen florid iyonu, günümüzde çoğu ağız bakım materyallerinin ve birçok restoratif materyalin yapısında bulunmaktadır. Bu restoratif materyaller ile gerçekleştirilen in vitro çalışmalar; ilk aşamada yüzey çözünmesine bağlı olarak hızlı bir florid salınımı gerçekleştiğini, son- 
rasında ise daha yavaş ve difüzyon-kontrollü bir şekilde salınımın devam ettiğini göstermiştir. Bu materyaller, topikal bir kaynağın varlığında fluorid reşarjı yapabilmektedir. Bununla birlikte, florid iyonları çözündüğünde matriks yapısında boşluk bırakıyor olması, dezavantaj olarak değerlendirilmektedir. Bu bağlamda, biyoaktif özellikli çeşitli restoratif materyallerin hem kalsiyum hem de florid için iyi bir iyon kaynağı olabileceği belirtilmiştir. ${ }^{33}$

Diş çürüklerini önlemek için kalsiyum ve fosfat iyonlarının salınımını yapan materyallerin de ön plana çıktığı bilinmektedir. Kalsiyumfosfat (CaP) partiküllerinin rezine eklenmesi ile oluşturulan kompozitler, $\mathrm{Ca}$ ve $\mathrm{PO}_{4}$ iyon salınımı yaparak hidroksiapatit $\left[\mathrm{Ca}_{10}\left(\mathrm{PO}_{4}\right)_{6}\right.$ $(\mathrm{OH})_{2}$ ] oluşumunu sağlamaktadır. ${ }^{34} \mathrm{CaP}$ materyallerinin dentin ve mine remineralizasyonuna etkisi kanıtlanmıştır. ${ }^{35}$

Cheng ve ark., (2017), çürük önleyici özellikleri olan yeni jenerasyon biyoaktif rezinlerle ilgili çalışmaları inceleyen bir makale yayınlanmıştır. ${ }^{36}$ Makalede, gümüş nanopartiküllerinin (NAg) küçük boyutları ve yüksek yüzey alanları sayesinde antimikrobiyal özellikleri güçlendirdiği belirtilmiştir. Ayrıca antibakteriyal maddelerin moleküler zincirlerinin uzatılmasının tükürük kaynaklı biyofilmlerin metabolik aktivitesini ve asit ürünlerini azalttığı vurgulanmıştır. Zincir uzunluğu 16 olan dimetilaminoheksadesil metakrilat (DMAHDM)'ın en güçlü antimikrobiyal etkiyi gösterdiği bildirilmiştir. ${ }^{37}$ Çalışmalarda kullanılan diğer bir molekül olan 2metakriloiloksietil fosforilkolin (MPC)'in ise polimerlerinin hidrofilik olduğu ve dental kullanımında protein itici bir görev yaptıkları belirtilmiştir. ${ }^{38}$ Makalede geçen iki araştırmada rezinlerin içerisine biyoaktif ajanlar konulmuş ve antibakteriyel etkinlikleri, remineralizasyon kapasiteleri incelenmiştir. Melo ve arkadaşları; bu iki antibakteriyal ajanı (NAg, DMAHDM) ve bir remineralizasyon ajanını [amorf kalsiyum fosfat (NACP)] kompozitlere eklemiştir. ${ }^{39}$ Zhang ve arkadaşları ise MPC, DMAHDM, NAg, NACP olmak üzere 4 ajanı rezin modifiye cam iyonomer içerisine eklemişlerdir. ${ }^{40}$ Sonuçlar doğrultusunda kalsiyum ve fosfat salınımının arttığı, biyofilm kolonizasyonun azaldığı belirtilmiştir. Konuyla ilgili daha fazla çalışma gerektiğini belirtilerek diş çürüklerini önlemek için simanlara, sealentlara ve kompozitlere biyoaktif ajanların eklenebileceğini vurgulamışlardır. Makalede geçen diğer bir çalışmada ise Wang ve ark., (2016), sınıf V kavitelerde kullanılmak üzere biyoaktif bir kompozit geliştirilmesini konu almıştır. ${ }^{41}$ Subgingival marjindeki sınıf $\mathrm{V}$ restorasyonların temizliğinin zor olduğu ve periodontal bakterilerin bu bölgede çoğalmasına zemin hazırlayarak cep oluşumuna neden olabileceği belirtilmiştir. Üretilen bu rezin matriksin, kalsiyum ve fosfat iyonlarını reşarj edebildiği ve yeniden salınımını sağlayarak bu soruna çözüm üretmeyi amaçladıklarını bildirmişlerdir. İçeriğine antibakteriyel etkinliğinden dolayı DMAHDM, MPC ve NACP partiküllerini eklediklerini belirtmişlerdir. Çalışmanın sonucunda, üretilen kompozitin, periyodonsiyumun korunmasına katkıda bulanacağını düşündüklerini ifade etmişlerdir. ${ }^{36}$

Ulusal Dental ve Kraniofasiyal Araştırma Enstitüsü (National Institute of Dental and Craniofacial Research), tarafından gerçekleştirilen bir çalışmada, kompozit restorasyonların beklenen ortalama ömrünün 5-7 yıl olduğu, bu durumun asıl nedeninin materyal-diş arayüzündeki bonding ajanının başarısızlığından kaynaklandığı rapor edilmiştir. ${ }^{42}$ Bonding konusu kavite preperasyonlarının değişmesi, sağlıklı olan diş dokularının ve yapılarının korunmasına daha fazla odaklanıması gibi büyük değişikliklere ışık tutmasına rağmen, bu bağlantı arayüzü restorasyonların en güçsüz bölgesi olarak kabul görmeye devam etmektedir. ${ }^{43}$

Minimal restoratif tedavilerde kullanılan biyoaktif materyaller, biyolojik çevreden pozitif bir cevap uyandırmak ve diş dokularının korunmasını ve remineralizasyonunu sağlamak için bağlantı arayüzüne spesifik iyonların salınımını yapabilmektedirler. ${ }^{44} \mathrm{Bu}$ materyallerin uygulanmasının, restoratif materyal ve çevresindeki diş dokuları arasında da başarılı bir bağlantı sağlayabildiği bildirilmektedir. Oluşan apatit formasyonu (Şekil 1) bağlantıyı kuvvetlendirmektedir. Biyoaktif materyaller, su taşıma özelliği ile diş yapısı için oldukça önemli olan mineral iletimini sağlamakta, mineralizasyonu stimüle etmekte ve mikrosızıntıyı önleyen kimyasal bağlanma gerçekleştirmektedir. ${ }^{22}$

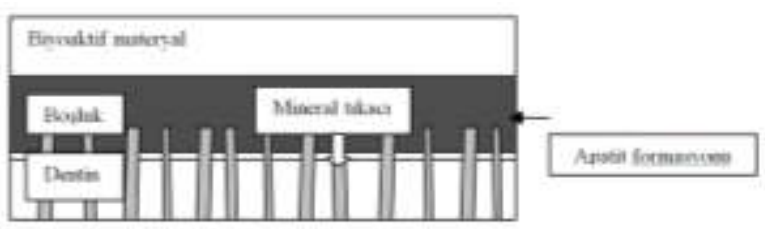

Şekil 1. Biyoaktif materyal ile materyal arayüzünde apatit benzeri tabaka oluşumu

Restoratif diş hekimliğinde adeziv monomerlerin kullanımı uzun yıllar boyunca tartışmalı bir konu olarak kalmıştır. Rezin-dentin adeziv sistemlerinin uzun süreli klinik performansının üstünlüğü, prospektif klinik çalışmalarda gösterilmiştir. ${ }^{45}$ Mine-dentin adezivleri ile 1980, 1990 ve 2000'li yılların başlarında yapılan birçok 
prospektif klinik çalışma, bu adezivlerin kompozit rezinler ile kullanımındaki performansının kabul edilebilir düzeyde olduğunu göstermiştir. ${ }^{46,47}$ Diğer taraftan, daha güncel, randomize ve kontrollü klinik çalışmaların daha az olumlu sonuç verdikleri belirtilmiştir. ${ }^{48}$ Adeziv rezin-dentin arayüzünü test etmek için kullanılan gelişmiş analitik teknikler; başarılı bir dentin bonding işlemini olumsuz etkileyebilecek birçok etken göstermiştir. ${ }^{49}$ Bu etkenler; rezin-dentin kollajen hibrit bölgesindeki "su ağacı" formasyonundan ötürü gecikmiş hidrolizisin ters etkilerini ve dentinin asidik demineralizasyonu ile salınan metalloproteinaz enzimlerinin reaktivasyonu ile kollajen yapının enzimatik bozulmasını içermektedir. ${ }^{8}$ Adeziv sistemlerin mineye ve dentine mikromekanik ve kimyasal yolla bağlanabilmesine rağmen klinik uygulama sırasındaki hassasiyet gereksinimleri nedeniyle diş dokusuna bağlanmalarında klinisyenin uzmanlığı ile orantılı olarak çeşitli sorunlar gözlenebileceği de bildirilmiştir. ${ }^{50}$ Adezivler ve kompozit rezinlere dair gelişmeler bu sorunlara değinse de, bu tip dezavantajların diş yapısı ve restorasyon arasında daha stabil bir arayüz oluşmasını sağlayabilecek alternatif mekanizmaların araştırılması için bir potansiyel niteliğinde olduğu bildirilmiştir. ${ }^{8}$

Abuna ve ark., (2016), kalsiyum fosfat mikro doldurucuları ve fosfoprotein biyomimetik analog takviyeli self-etch primerleri içeren deneysel bir adezivin bonding performansını ve dentin remineralizasyon potansiyelini incelemişlerdir. ${ }^{51}$ Araştırmacılar rezin-dentin arayüzünün bonding ömrünün, hibrid tabaka içindeki minerali tükenmiş dentin kollajenin terapötik remineralizasyonu ile arttırılabileceğini ve dentin fosfoproteinlerinin biyomimetik analoglarını içeren, iyonize kalsiyum ve fosfat iyonlarını salabilen rezin bazı materyallerin kullanımının intrafibriler kollajen remineralizasyonunu uyarabileceğini bildirmişlerdir. $^{52} \mathrm{Ca} / \mathrm{P}$ takviyeli adezivin kullanımından sonra rezindentin arayüzündeki nanosızıntının azaldığı da belirtilmiştir. ${ }^{51}$

Bonding ajanlarına olan ihtiyacın ortadan kalkmasına dair en çarpıcı çalışma Chatzistavrou ve ark., (2014) tarafından yapılmıştır. Yeni bir biyoaktif ve antibakteriyel özellikli kompozit rezin materyal üretmek için yapılan bu çalışmada gümüş (Ag) takviyeli biyoaktif cam (AG-BC) ile akışkan kompozitleri farklı ölçülerde birleştirerek yeni bir kompozit üretmişlerdir. Silika bazlı bir materyal olan AG-BC'nin biyoaktivitesini $37^{\circ} \mathrm{C}^{\prime}$ lik SVS solüsyonunda 20 gün boyunca test ettiklerini belirtmişlerdir. Diş dokusuna bağlanma kuvvetinde yeni üretilen kompozitler ile kontrol grubu kompozitlerinin arasında anlamlı bir farklılık saptamamalarına rağmen bakterisidal etkinin Ag iyon salınımı ile ilgili olduğu vurgulanmıştır. Antibakteriyal özelliğinin yüksek olması dolayısıyla $E$. coli ve $S$. mutans'a karşı antimikrobiyal özellik gösterdiğini bildirmişlerdir. Antimikrobiyal özelliğin \%''lik ve \%15'lik AG-BC ilaveli kompozitlerde görüldüğü belirtilmiştir. Deneysel olarak üretilen bu kompozitin, gümüş oksidasyonu nedeniyle ön grup dişlerde kullanılamasa bile arka grup dişler için olumlu olabileceğini bildirmişlerdir. Bunun yanı sıra, apatit oluşturabilen biyoaktif özelliğinden ve komşu diş dokularıyla olan bağlantısından dolayı bonding ajanlarına olan ihtiyacı ortadan kaldırmak için öncülük edebileceğini savunmuşlardır. AG-BC içerikli kompozitin, ikincil çürükleri önleyebileceği gibi diş sert dokularının remineralizasyonuna da yardımcı olabileceği de ifade edilmiştir. $^{22}$

\section{Biyoaktif Restoratif Materyallerin Mekanik Özelliklerinin Değerlendirilmesi}

Dental materyaller, restorasyonların performansını artırmak için yeni özellikler ile güçlendirilse de çeşitli sorunların halen görüldüğü belirtilmiştir. ${ }^{8}$ İlk biyoaktif camın geliştirilmesinin üzerinden yaklaşık 40 yıl geçmesine rağmen, biyoaktif camların rezin bazlı kompozitlerde kullanılma potansiyelinin yakın zamanda araştırılmaya başlandığı bildirilmiştir. ${ }^{26}$ Biyoaktif özelliklerle geliştirilen yeni materyallerin antibakteriyal ve biyoaktivite özelliklerinin yanında mekanik özelliklerinin de mutlaka incelenmesi gerektiği vurgulanmıştır. ${ }^{53}$

Kütle çatlaklarına çözüm önerisi sunan, biyoaktif ve akıllı karakterdeki deneysel bir kompozit üretimine dair yapılan çalışma Xu ve ark., (2010)'na aittir. $\mathrm{Xu}$ ve ark., hidroksiapatit oluşumu için $\mathrm{Ca}$ ve $\mathrm{PO} 4$, iyon salınımı için tetrakalsiyum fosfat [TTCP: $\mathrm{Ca}_{4}\left(\mathrm{PO}_{4}\right)_{2} \mathrm{O}$ ] ve estetik özellik için cam partikülleri ekleyerek estetik bir kalsiyum fosfat kompozit üretimi amacıyla bir çalışma yapmışlardır. TTCP'nin bütün CaP bileşikleri arasında en alkali olduğu ${ }^{54}$, bu özelliği sayesinde zararlı asitleri tamponlayabileceği ve diş çürüklerini önleyebileceği vurgulanmıştır. Çalışmada elde edilen rezin matriksin, yük taşıma kapasitesinin ve çürük önleme potansiyelinin de yüksek olması nedeniyle TTCP-cam kompozitin restoratif materyaller açısından önemli bir gelişme olduğu belirtilmiştir. Bu kompozitin, $\mathrm{pH}$ nötralden karyojenik değer olan 4'e düştüğünde akıllı bir şekilde iyon salınımı sağladığı bildirilmiştir. Eklenen cam partiküllerin, materyalin mekanik özelliğini geliştirerek diğer iyon salınımı sağlayan materyallere kıyasla daha başarılı sonuçlar verdiği ve kompozit kütle çatlaklarına bir çözüm olabileceği belirtilmiştir. ${ }^{35}$ 
Caluwé ve ark., (2016), ise iki adet fluorid içeren biyoaktif camın biyoaktifliğini ve biyouyumluluğunu karşılaştırmak için yaptıkları araştırmalarında, sodyum (Na) içeren $45 \mathrm{~S} 5 \mathrm{~F}$ ve $\mathrm{Na}$ içermeyen CF9 biyoaktif camları kullanmışlardır. Materyaller 7 gün boyunca SVS'de bekletilerek biyouyumluluğu test edilmiştir. CF9'un biyoaktif potansiyelinin yüksek kalsiyum salınımı ve hidroksiapatit oluşturma özelliği nedeniyle daha yüksek olduğunu bildirmişlerdir. ${ }^{13}$ Yaptıkları diğer bir araştırmada, (2017), cam iyonomer simanların biyoaktivitesini yükseltmek ve uzun dönemdeki mekanik özelliklerini geliştirmek için içerisine florid içerikli iki biyoaktif camı (45S5F ve CF9) eklemişlerdir. Biyoaktif cam ilavesinin hidroaksiapatit oluşumuna bağlı olarak biyoaktiviteyi yükselttiğini, özellikle CF9 eklenen cam iyonomer simanların biyoaktivitesinin daha yüksek olduğunu bildirmişlerdir. Bununla birlikte, eklenen biyoaktif cam miktarının artması ile basınç dayanıklıığının azaldığını belirtmişlerdir. ${ }^{17}$

Biyoaktif rezin modifiye cam iyonomer simanların mekanik özelliklerini karşılaştırmak adına Korkut ve ark.,(2017), Photac Fil Quick Aplicap (3M ESPE, Minnesota, ABD), GC Fuji II GP (GC Corporation, Tokyo, Japonya), Riva Light Cure (SDI, Illionis, ABD) ve ACTIVA Bioactive (Pulpdent Corporation, Watertown, $A B D$ ) olmak üzere dört farklı rezin modifiye cam iyonomer siman üstünde bir çalışma yapmışlardır. Elde edilen sonuçlar doğrultusunda Activa Biyoaktif Restoratif materyalin diğer rezin modifiye cam iyonomer simanlara göre daha iyi mekanik ve fiziksel özellik gösterdiği bulunmuştur. Bu sonuca rağmen materyalin klinik performansının doğrulanması için klinik çalışmalar yapılması tavsiye edilmiştir. ${ }^{55}$

Chen ve ark., (2016), cam iyonomer siman ve kalsiyum silikaların kombinasyonundan oluşan biyoaktif nitelikli bir dental materyal oluşturmak için çalışmışlardır. Araştırmalarında, Wollastonite (kalsiyum silikaCS) ve MTA'yı, iki tip kontrol cam iyonomer simanı ile birleştirmişlerdir. Materyallerin sertleşme zamanlarını, basınç dayanıkıııklarını, pH'larını ve biyoaktivitelerini kıyaslamışlardır. Modifiye simanlar üzerinde apatit kristalleri gözlemlediklerini, kontrol simanlarında bu yapıya rastlamadıklarını bildirmişlerdir. Modifiye simanın basınç dayanıkılığının, eklenen Wollastonite veya MTA ile ilişkili olmadığı belirtilirken; \%20'lik (veya daha az) Wollastonite veya MTA kullanımında basınç dayanıkııı̆ının aynı kaldığı; fakat \%20'lik MTA içeren modifiye simanın 14 gün boyunca distile suda bekletildiğinde basınç dayanıklıı̆ının yükseldiği bildirilmiştir. Sertleşme zamanlarının ise modifiye cam iyonomer simanlarda uzadığı belirtilmiştir. ${ }^{56}$
Başka bir çalışmada (2014), polimer matriks içerisindeki biyostabil ve biyoaktif cam doldurucuların silanizasyonunun, kompozitlerin bazı fiziksel özellikleri üzerine olan etkisi araştırımıştır. Çalışma in vitro olarak yapılmış ve cam içermeyen kontrol grubu, silanize olmayan biyoaktif cam, silanize biyoaktif cam, silanize olmayan biyostabil cam ve silanize biyostabil cam olmak üzere beş farklı grup değerlendirilmiştir. Silanlama işleminin, iki tip cam partikülünün de, polimerin de çözünürlüğünü düşürdüğü belirtilmiştir. Uygulanan üç nokta bükme testi sonuçlarına göre ise cam doldurucular arttıkça esneme kuvveti, sertliği ve modülünde düşüş olduğu ifade edilmiştir. ${ }^{57}$

\section{Biyoaktif Materyallerin Sitotoksik Etkilerinin İncelenmesi}

Biyoaktivitenin diğer bir avantajı ise osteoblastik aktiviteyi artırmasıdır. Filogenetik çalışmalar, evrim boyunca orijinal dentin analoglarının alveol içindeki osteoblast/odontoblast benzeri hücreleriyle, kemiğin lakünaları içindeki osteositlerin oldukça benzer olduğunu göstermiştir. Bu organizasyonun adına osteodentin dendiği ve kemirgenler gibi bazı memeli türlerinde veya insanlarda reperatif dentin olarak diş gelişimi sırasında gözlendiği bildirilmiştir. Her ne kadar kemik ve diş arasında çeşitli benzerlikler olsa da, iki yapının aynı zamanda kendilerine ait özellikler gösterdiği belirtilmiştir. $^{58}$

Bu bilgiler ışığında Choi ve ark., (2008), biyoaktif nitelikteki (70SiO2, 25CaO, 5P2O5) sol jel metoduyla üretilmiş camları (SC), cam iyonomer siman (CIS, Fuji I) ile biyoaktiviteyi ve dental hücrelerin rejenerasyon kapasitesini artırmak için karıştırarak deneysel bir cam iyonomer siman üretmişlerdir. \%10 ve $\% 30$ oranlarında üretilen SC/CIS simanların sertleşme süresi, çapsal gerilim direnci ve in vitro biyoaktivitesi test edilmiştir. Eklenen SC cam iyonomer simanın çapsal gerilim direncini değiştirmediği bildirilmiştir. Örneklerin SVS'ye batırılmasından sonra yüzeyde apatit mineral fazının çökelmesinin indüklendiği; fakat cam iyonomer siman üzerinde herhangi bir mineral indüksiyonu gözlenmediği belirtilmiştir. In vitro hücre deneyinin, biyoaktif cam içeren cam iyonomer simanın cam iyonomer siman örneğine göre 7 güne kadar yapılan hücre kültüründe daha yüksek hücre canlılığı gösterdiğini kanıtladığı vurgulanmıştır. Siman örnekleri üzerindeki hücre canlılığını ölçmek için fareden türetilmiş osteoblastik hücrelerin (MC3T3-E1) kullanıldığı belirtilmiştir. Sol jel metoduyla hazırlanan camlar da dahil olmak üzere biyoaktif camların hücre büyümesini ve osteoblastik farklılaşmayı stimüle ettiği önceki kaynaklarda 
vurgulanmıştır. Bu bağlamda, yapılan çalışmada eklenen biyoaktif camın osteoblastik hücre büyümesini biyoaktif substrat yoluyla direkt olarak veya iyon salınımı yoluyla indirekt olarak etkilemiş olabileceği, fakat materyalin ilk hücre büyüme evresinde avantajlı bir role sahip olduğunun kanıtlandığı vurgulanmıştır. Ayrıca diş yapısının rejenerasyonunu desteklediği belirtilmiştir. $^{59}$

Biyoaktif camların sitotoksisitesine dair literatürde oldukça az çalışma gözlenmektedir. Salehi ve ark., (2015), biyoaktif cam dolduruculu kompozitlerin sitotoksisitesini in vitro olarak araştırmışlardır. Araştırmada kompozitlere BAC65 ve BAC61 olmak üzere iki biyoaktif cam eklenmiştir. Kompozitlerin sitotoksisitelerinin içeriklerinden bağımsız olarak kültürdeki hücrelerin canlılığını azaltmada eşdeğer seviyede olduklarını belirlemişlerdir. Kompozitlerin sitotoksisitelerinin materyal içeriğindeki BAC ile ilişkili olmadığı, salınan artık monomerler ile ilişkili olduğu vurgulanmıştır. ${ }^{60}$

\section{SONUÇ}

Biyoaktif materyallerin; gerekli mineralleri (kalsiyum, fosfat vb.) ortama sağlayarak doğal remineralizasyonu teşvik ettiği, remineralizasyon sayesinde dişin yapısını güçlendirdiği ve asit saldırılarına karşı dişin korunmasına yardımcı olduğu görülmektedir. Bu özellikteki materyallerin, diş ve materyal arasında kuvvetli bir sızdırmazlık sağlayarak sekonder çürüklerin oluşmasını engelleyebildiği in vitro çalışmalar ile gösterilmiştir. Rejenerasyon özelliğine sahip olmaları da diş hekimliği açısından önemlerini artırmaktadır.

Son dönemlerde, dentinde adezyon, integrasyon ve sızdırmazlık konusundaki mekanizmalar, biyoaktif materyal teknolojisinin çalışma alanını oluşturmaktadır. Biyoaktivite özellikli bu materyallerin restoratif diş hekimliğinde yenilikler yaratmaya aday oldukları ve yakın gelecekte diş tedavilerinde daha başarılı alternatifler oluşturacakları; bu nedenle biyoaktif materyallerin restoratif alanda kullanımlarının giderek yaygınlaşacağı, fakat bu alanda daha fazla klinik araştırılmalara gerek olduğu düşünülmektedir.

NOT: Calışmada herhangi bir yazar, kurum ya da kuruluş ile çıkar çatışması içerisinde bulunmamaktadır. Makale daha önce hiçbir yerde yayınlanmamış ve yayınlanmak üzere işlem görmemektedir

\section{KAYNAKLAR}

1. Abdelkarim G, Soumaya B, Naima E, Mohammed $\mathrm{B}$, Abdellah $\mathrm{H}$. What is a bioactive compound? A combined definition for a preliminary consensus. Int J Food Sci Nutr 2014;3:174-9.

2. Snehal $S$, Rucheet P. Bioactive materials in conservative dentistry. Int J of Contemp Dent Medl Rev vol.2015. Article ID 340115, 2015. doi: $10.15713 /$ ins.ijcdmr.47

3. Jefferies SR. Bioactive Dental Materials. Inside Dentistry 2016;12:1-3.

4. Hench LL. An Introduction to Bioceramics. 2 ed. Singapore;World Scientific: 1993. p.7-8.

5. Greenspan DC, Zhong JP, Latorre GP. Effect of surface area to volume ratio on in vitro surface reactions of bioactive glass particulates. Bioceramics 1994;7:28-35.

6. Gerhardt LC, Boccaccini AR. Bioactive Glass and Glass-Ceramic Scaffolds for Bone Tissue Engineering. Materials 2010;3:3867-910.

7. Siriphannon $P$, Kameshima $Y$, Yasumori A, Okada K, Hayashi S. Formation of hydroxyapatite on CaSiO3 powders in simulated body fluid. J Eur Ceram Soc 2002;22:511-20.

8. Jefferies SR. Bioactive and biomimetic restorative materials: a comprehensive review partI. J Esthet Restor Dent 2014;26:14-26.

9. Mehta $A B$, Kumari $V$, Jose $R$, Izadikhah $V$. Remineralization potential of bioactive glass and casein phosphopeptideamorphous calcium phosphate on initial carious lesion: An in-vitro $\mathrm{pH}$ cycling study. J Conserv Dent 2014;17:3-7.

10. Zhong Y, Liu J, Li X, Yin W, He T, Hu D, Liao Y, Yao $X$, Wang $Y$. Effect of a novel bioactive glassceramic on dentinal tubule occlusion: $A n$ in vitro study. Aust Dent J 2014;60:96-103.

11. Yang SY, Kwon JS, Kim KN, Kim KM. Enamel surface with pit and fissur sealent containing $45 \mathrm{S5}$ bioactive glass. J Dent Res 2016; 95:550-7.

12. Cakan EF, Eren MM, Günal Ş. Restoratif diş hekimliğinde biyoaktif materyaller. Turkiye Klinikleri J Restor Dent-Special Topics 2018;4:4652.

13. Caluwé TD, Vercruysse CWJ, Declercq HA, Schaubroeck D, Verbeeck RMH, Martens LC. Bioactivity and biocompatibility of two fluoride containing bioactive glasses for dental applications. Dent Mater 2016;32:1414-28.

14. Kamitakahara MK, Tadashi K, Takashi N. Effect of polyacrilic acid on apatite formation of a bioactive ceramic in a stimulated body fluid: fundamental examination of the possibility to obtaining bioactive glass-ionomer cements for orthopaedic use. 
Biomaterials 2001;22:3191-6.

15. Hicks J, Garcia-Godoy F, Donly K, Flaitz C. Fluoride-releasing restorative materials and secondary caries. J Calif Dent Assoc 2003;31:22945.

16. Randall RC, Wilson NH. Glass-ionomerrestoratives: a systematic review of a secondary caries treatment effect. J Dent Res 1999;78:628-37.

17. Caluwé TD, Vercruysse CWJ, Ladik I, Convents R, Declercq $H$, Martens LC, Verbeeck RM. Addition of bioactive glass to glass ionomer cements: Effect on the physico-chemical properties and biocompatibility. Dent Mater 2017;33:186-203.

18. Hench LL. The story of Bioglass. J Mater Sci Med 2006;17:967-78.

19. Maryam K, Fatema K. A review of glass-ionomers: From conventional glass-ionomer to bioactive glass-ionomer. Dent Res J 2013;10:411-20.

20. Yli-Urpo H, Narhi M. Compound changes and tooth mineralization effects of glass ionomer cements containing bioactive glass (S53P4), an in vivo study. Biomaterials 2005;26:5934-41.

21. Yli-Urpo $H$, Lassila LV, Närhi T, Vallittu PK. Compressive strength and surface characterization of glass ionomer cements modified by particles of bioactive glass. Dent Mater 2005;21:201-9.

22. Chatzistavrou $X$, Velamakanni $S$, DiRenzo $K$, Leflelidou A, Fenno JC, Kasuga T, Boccaccini AR, Papagerakis P. Designing dental composites with bioactive and bactericidal properties. Mater Sci Eng C 2015;52:267-72.

23. Drummond JL. Degradation, fatigue and failure of resin dental composite materials. J Dent Res 2008;87:710-9.

24. Takashaki Y, Imazato S, Russell RRB, Noiri Y, Ebisu $S$. Influence of resin monomers on growth of oral streptococci. J Dent Res 2004;83:302-6.

25. Spencer P, Ye Q, Misra A, Goncalves SEP, Laurence JS. Protheins, Pathogens and Faliure at the Composite-Tooth Interface. J Dent Res 2014; 93: $1243-94$

26. Khvostenko D, Hilton TJ, Ferracane JL, Mitchell JC, Kruzic J]. Bioactive glass fillers reduce bacterial penetration into marginal gaps for composite restorations. Dent Mater 2016;32:73-81.

27. Jain P, Kaul R, Saha S, Sakar S. Smart materialsmaking pediatric dentistry bio-smart. Int J Pedod Rehabil 2017;2:55-9.

28. Cooper GPR, Cassidy N, Nor JE, Sloan AJ, Smith AJ. The effection of calcium hydroxide on solubilisation of bioactive dentine matrix components. Biomaterials 2006;27:2865-2873.

29. Tomson PL, Grover IM, Lumley PJ, Sloan AJ, Smith AJ, Cooper PR. Dissolution of bioactive dentin matrix components by mineral trioxide aggregate. J Dent 2007;35:636-42.

30. Forsback AP, Areva S, Salonen JI. Mineralization of dentin induced by treatment with bioactive glass S53P4 in vitro. Acta Odontol 2004;62:14-20.

31. Duarte MA, Martins CS, de Oliveira Cardoso Demarchi AC, de Godoy LF, Kuga MC, Yamashita JC. Calcium and hydroxide release from different pulp capping materials. Oral Surg Oral Med Oral Pathol Oral Radiol Endod 2007;104:66-9.

32. Melo MAS, Weir MD, Rodrigues LKA, Xu HKK. Novel calcium phosphate nonocomposite with caries-inhibition in a human in situ model. Dent Mater 2013;29:231-40;

33. Davis HB, Gwinner F, Mitchell JC, Ferracane JL. Ion release from, and fluoride recharge of a composite with a fluoride-containing bioactive glass. Dent Mater 2014;30:1187-94.

34. Skrtic D, Hailer AW, Takagi S, Antonucci JM, Eanes ED. Quantitative assessment of the efficacy of amorphous calcium phosphate/methacrylate composites in remineralizing caries-like lesions artificially produced in bovine enamel. J Dent Res 1996;75:1679-86.

35. Xu HHK, Moreau JL. Dental glass-reinforced composite for caries inhibiton:Calcium Phosphate ion release and mechanical properties. J Biomed Mater Res B Appl Biomater 2010; 92:332-340.

36. Cheng L, Zhang K, Zhang N, Melo MAS, Weir MD, Zhou XD, Bai YX, Reynolds MA, Xu HHK. Developing a new generation of antimicrobial and bioactive dental resins. J Dent Res 2017;96:85563.

37. Zhang K, Cheng L, Weir MD, Bai YX, Xu HH. Effects of quaternary ammonium chain length on the antimicrobial and remineralizing effects of a calcium phospate nonacomposite. Int $\mathrm{J}$ Oral Sci 2016;8:45-53.

38. Zhang N, Ma J,Melo MA, Weir MD, Bai Y, Xu HH. Protein-repellent and antibacterial dental composite to inhibit biofilms and caries. J Dent 2015;43:225-34.

39. Melo MA, Orrego S, Weir MD, Xu HH, Arola DD. Designing multiagent dental materials for enhanced resistance to biofilm damage at the bonded interface. ACS Appl Mater Interfaces 
2016;8:11779-87.

40. Zhang N, Weir MD, Chen C, Melo MA, Bai Y, Xu $\mathrm{HH}$. Ortodontic cement with protein repellent antimicrobial properties and release pf calcium and phophate ions. J Dent 2016;50:51-9.

41. Wang L, Xie X, Imazato S, Weir MD, Reynols MA, $\mathrm{Xu} \mathrm{HH}$. A protein-repellent and antimicrobial nanocomposite for class $\mathrm{V}$ restorations to inhibit periodontitis related pathogens. Mater Sci Eng C Mater Biol Appl 2016;67:702-10.

42. Spencer P, Ye Q, Park J, Topp EM, Misra A, Marangos O, Wang $Y$, Bohaty BS, Singh V, Sene F, Eslick J, Camarda K, Katz JL. Adhesive/Dentin Interface: The Weak Link in the Composite Restoration. Ann Biomed Eng 2010;38:1989-2003.

43. Kumar JS, Jayalakshmi S. Bond failure and its prevention in composite restoration :A review. J Pharm Sci Res 2016;8:627-31.

44. Sauro S, Osorio R, Watson T, Toledano $M$. Therapeutic effects of novel resin bonding systems containing bioactive glasses on mineral-depletad areas within the bonded-dentine interface. J Mater Sci Mater Med 2012;23:1521-32.

45. Wilder AD Jr, Swift EJ Jr, Heymann HO, Ritter AV, Sturdevant JR, Bayne SC. A12-year clinical evaluation of a three-step dentin adhesive in non carious cervical lesions. J Am Dent Assoc 2009;140:526-35.

46. Barnes DM, Blank LW, Thompson VP, Holston AM, Gingell JC. A5-and 8-year clinical evaluation of a posterior composite resin. Quintessence Int 1991;22:143-51.

47. Demarco FF, Corrêa MB, Cenci MS, Moraes RR, Opdam NJ. Longevity of posterior composite restorations: not only a matter of materials. Dent Mater 2012;28:87-101.

48. Bernardo M, Luis $H$, Martin MD, Leroux BG, Rue T, Leitao J, DeRouen TA. Survivaland reasons for failure of amalgam versus composite posterior restorations placed in a randomized clinical trial. J Am Dent Assoc 2007; 138:775-83.

49. Liu Y, Tjäderhane L, Bresche L, Mazzoni A, Li N, Mao J, Pashley DH, Tay FR. Limitations in bonding to dentin and experimental strategies to prevent bond degradation. J Dent Res 2011;90:953-68.

50. Ülker HE, Tunçdemir MT, Erkan Aİ, Arslan Malkoç M, Çobanoğlu N. İki self-etch bonding sistemin biyouyumlulukların ve bağlanma dayanımlarının değerlendirilmesi. J Dent Fac Atatürk Uni 2014;24:44-9.
51. Abuna G, Feitosa VP, Correr AB, Cama G, Giannini M, Sinhoreti MA, Pashley DH, Sauro S. Bonding performance of experimental bioactive/biomimetic self-etch adhesives doped with calcium-phospate fillers and biomimetic analogs of phosphoproteins. J Dent 2016;52:79-86.

52. Sauro S, Osorio R, Watson TF, Tolenado $M$. Inluence of phosphoproteins' biomimetic analogs on remineralization of mineral depleted resindentin interfaces created with ion-releasing resin based systems. Dent Mater 2015;31:759-77.

53. Yoshihara K, Nagaoka N, Maruo Y, Sano $H$, Yoshida $Y$, Van Meerbeek B. Bacterial adhesion not inhibited by ion-releasing bioactive glass filler. Dent Mater 2017;33:723-34.

54. Chow LC. Calcium phospate cements:Chemistry, properties and applications. Mater Res Symp Proc 2000;599:27-37.

55. Korkut E, Gezgin O, Tulumbacı F, Özer H, Şener Y. Biyoaktif Rezin Modifiye Cam İyonomer Simanın Mekanik Özelliklerinin Karşılaştırmalı Değerlendirilmesi. EÜ Dişhek Fak Derg 2017; 38: 170-5.

56. Chen S, Cai Y, Engqvist H, Xia W. Enhanced of glass ionomer cement by incorporating calcium silicates. Biomatter 2016;1:1123842.

57. Oral O, Lassila LV, Kumbuloglu O, Vallittu PK. Bioactive glass particulate filler composite: Effect of coupling of fillers and filler loading on some physical properties. Dent Mater 2014;30:570-577.

58. Goldberg $M$, Kulkarni $A B$, Young $M$, Boskey $A$. Dentin: structure, composition and mineralization. Front Biosci (Elite Ed). 2011;3:711-35.

59. Choi JY, Lee HH, Kim HW. Bioactive sol-gel glass added ionomer cement for the regeneration of tooth structure. J Mater Sci: Mater Med 2008;19:3287-94.

60. Salehi S, Gwinner F, Mitchell JC, Pfeifer C, Ferracane JL. Cytotoxicity of resin composites containing bioactive glass fillers. Dent Mater 2015;31:195-203.

\section{Yazışma Adresi}

Dok. Öğr. Dilara YÜREKTEN

İstanbul Üniversitesi Diş Hekimliği Fakültesi

Pedodonti ABD

Topkapı Mah. Turgut Özal Milet Cad. Kat:3

Fatih/İSTANBUL

e-mail: dilara_yurekten@hotmail.com 